\title{
Stress and Deflection Analysis of Belleville Spring
}

\author{
${ }^{1}$ H.K.Dubey, ${ }^{2}$ Dr. D.V. Bhope \\ ${ }^{I}$ Pg Student of Dept of Mechanical Engineering R.C.E.R.T, Chandrapur, India \\ ${ }^{2}$ Professor, Dept of Mechanical Engineering R.C.E.R.T, Chandrapur, India
}

\begin{abstract}
Abstrac: This paper reports stress and deflection analysis of a Belleville Spring using finite element method. The different combinations of ratios of its outer diameter and inner diameter i.e. $(D / d)$ and its Height to

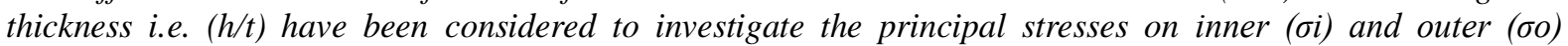
surfaces of the spring along with the deflections. Finite element method is used for analysis. The FE results are compared with existing analytical results.
\end{abstract}

Keywords: Stress, Deflection, Finite element method, Belleville Spring

\section{Introduction}

A Belleville spring, disc spring, Belleville washer, conical compression washers are all names for the same type of spring. It has a frusto-conical shape which gives the washer a spring characteristic. Belleville washers are typically used as springs, or to apply a pre-load or flexible quality to a bolted joint or bearing. A conical washer can be stacked to create a powerful compression spring. The Belleville washer is often used to support applications that have high loads and insufficient space for a coil spring. Disc springs are conical shaped washers designed to be loaded in the axial direction only. The spring geometry consists of four parameters namely Internal Diameter (d), Outer Diameter (D), Thickness (t), and Height (h) which is shown in figure 1.

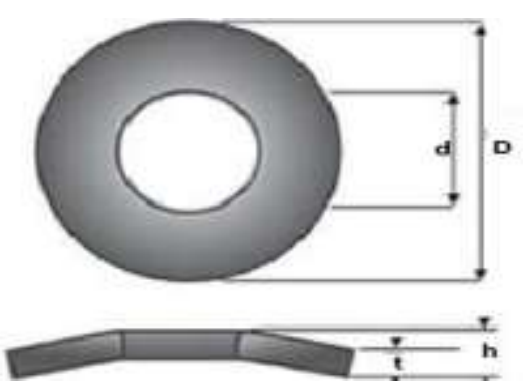

Figure 1: Front view\& Top view of a Belleville Spring

A Belleville spring experiences a deflection and stress when a load is applied in the axial direction. It has a very non-linear relation between the load applied and the axial deflection. The stress distribution is nonuniform for this spring. The axial force is applied at the periphery of the inner diameter due to which the stresses are induced at the inner surface $\&$ at the outer surface, which depends on geometric parameters. The deflections and the stresses induced at the inner surface and at the outer surface depend on the ratios of its height to thickness $(\mathrm{h} / \mathrm{t})$ and its outer diameter to inner diameter $(\mathrm{D} / \mathrm{d})$. This work deals with the deflection and the stresses induced in Belleville spring due to constant axial force acting on the inner surface of the conical spring for various ratios of $(\mathrm{h} / \mathrm{t}) \&(\mathrm{D} / \mathrm{d})$.

II.

\section{Literature Review}

Many researchers have carried out stress and deflection analysis of a Belleville spring. Monica Carfagni ${ }^{[1]}$ carried out the stress and deflection analysis to prepare a CAD method for the checkout and design of the Belleville springs. The method eliminates the need to resort to conventional trial-and-error techniques. In a matter of seconds, it rapidly and accurately checks out and designs Belleville springs, outputting the loaddeflection characteristics in graphic and table formats and can generate a dimensioned drawing. G. Schrfmmer ${ }^{[2]}$ carried out the stress and deflection analysis of a slotted Belleville spring to develop a analytical relationship for deflection and stress of a slotted conical spring.

\section{Introduction To Problem, Scope \& Methodology}

Though the geometry of the Belleville spring appears to be simple with conical shape but the stress distribution is quiet complex due to the axial load. It is predicted that the axial load is responsible for axial compressive stress and also for bending stress induced in the Belleville spring. The analytical equations are 
derived largely on the basis of bending moments to simplify the derivations. In finite element analysis it is possible to model the exact geometry of the spring and to investigate the effect of axial load on the stresses, and deflections of the spring. Hence it is possible to determine the exact values of stresses in Belleville spring which are induced on account of the combination of axial stress and bending stress.

Therefore, the present work deals with the determination of stresses and deflection in Belleville spring using FEA. The results obtained from FE analysis are compared with existing analytical equations. This study will lead to justify the validity of existing analytical equations and to estimate the conditions where it may become error prone. The scope \& methodology is described as follows:

- In the Present research work an approach for the analysis of a Belleville Spring has been carried out under axial compressive load (static axial load of $1000 \mathrm{~N}$ has been considered for analysis).

- The Various geometrical parameters of a Belleville Spring i.e. D, d, h \& t have been varied to investigate the stresses and the deflections induced in the Belleville spring. Following ratios are considered for analysis:-

$\mathrm{D} / \mathrm{d}=1.2,1.5,2,2.5,3,3.5,4,4.5,5 \& \mathrm{~h} / \mathrm{t}=1.25,1.5,1.75,2,2.25,2.5,2.75,3$

- Lastly, the FE results have been compared with the existing analytical equations available for the Belleville Spring and an effort have been made to show the variations in the stresses and deflections with respect to the geometrical parameters and an attempt have been made to establish certain relations which will help to evaluate the stresses \& deflection for any geometry of a Belleville Spring with accuracy. The load deflection characteristic is also investigated.

\section{Finite Element Analysis Of Belleville Spring}

In this work a simple Belleville Spring analysis has been done. For Each ratio of D/d, all h/t ratios have been varied to calculate the Deflection, principal stresses on Inner and Outer surface which are induced in the spring. Outer Diameter of Belleville Spring is considered as $125 \mathrm{~mm}$ and Height of the spring is considered as 5 $\mathrm{mm}$. A constant Force of $1000 \mathrm{~N}$ has been applied on the inner surface of the spring in Y-direction. The analysis is done by imposing boundary conditions such that the spring could deflect only along X\&Z-direction. The analytical equations for deflection \& stresses are given in equations (1) to (6):

$$
\begin{aligned}
& F=\frac{4 E \delta}{1-\mu^{2} \times M \times D^{2} \times\left[(h-t)\left(h-\frac{\delta}{2}\right) t+t^{3}\right]} \\
& M=\frac{6}{3.14 \log e(D / d)} \times\left[\frac{(D / d)-1}{D / d}\right]^{2} \\
& \sigma_{i}=\frac{4 E \delta}{1-\mu^{2} \times M \times D^{2}}\left[C_{1}\left(h-\frac{\delta}{2}\right)+C_{2} t\right] \\
& \sigma_{0}=\frac{4 E \delta}{1-\mu \mu^{2}}\left[C_{1}\left(h-\frac{\delta}{2}\right)-C_{2} t\right] \\
& C_{1}=\frac{6}{3.14 \log e \frac{D}{d}\left[\frac{(D / d)-1}{\log e(D / d)}-1\right]} \\
& C_{2}=\frac{6}{3.14 \log e \frac{D}{d}}\left[\frac{(D / d)-1}{2}\right]
\end{aligned}
$$

Where $\mathrm{M}, \mathrm{C}_{1}, \mathrm{C}_{2}$ are Constants, $\mathrm{E}=$ modulus of Elasticity $\left(2 * 10^{5} \mathrm{Mpa}\right)$ and $\mu=$ poisons ratio $(0.3)$. The representative stress and deformation contours for principal stresses on inner \& outer surface along with the deflection are shown in figures $2,3, \& 4$ as an illustration for $\mathrm{D} / \mathrm{d}=1.5 \& \mathrm{~h} / \mathrm{t}=1.5$. The load- deflection characteristic of the spring is also studied for the ratio of $\mathrm{D} / \mathrm{d}=2 ; \mathrm{h} / \mathrm{t}=1.5$ and $\mathrm{D} / \mathrm{d}=4 ; \mathrm{h} / \mathrm{t}=1.5$. The force is varied from $100 \mathrm{~N}$ to $1000 \mathrm{~N}$ for load deflection characteristics. The results are presented in forthcoming sections. 


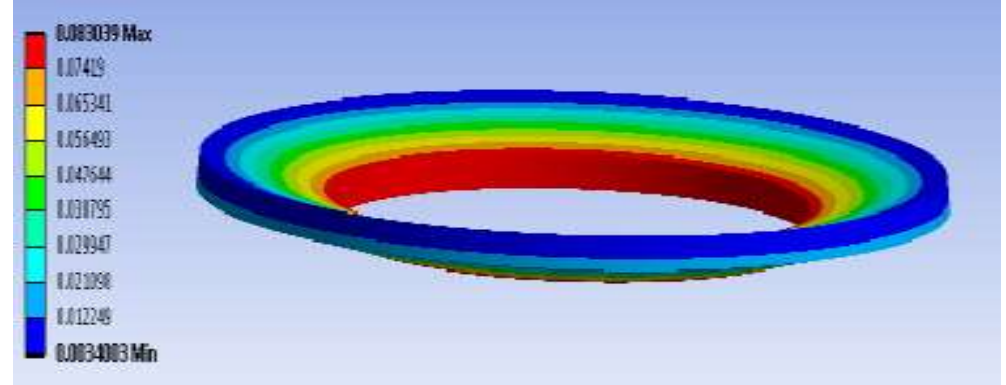

Figure 2: Deformation (Deflection) of a Belleville spring (mm)

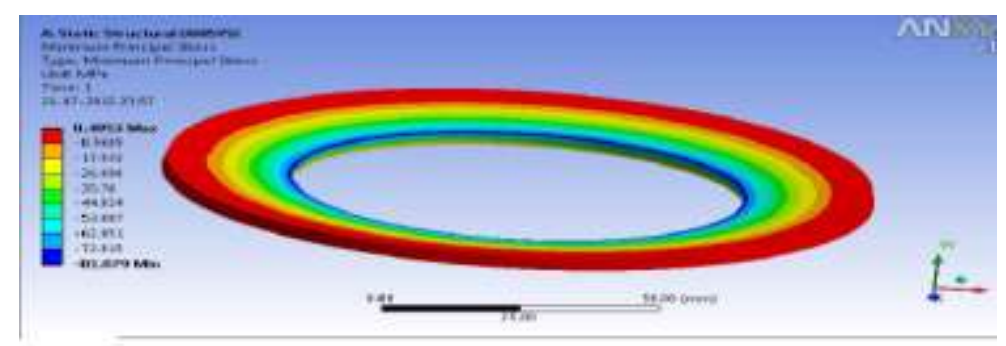

Figure 3: Minimum Principle Stress Contour at the Inner Surface (MPa)

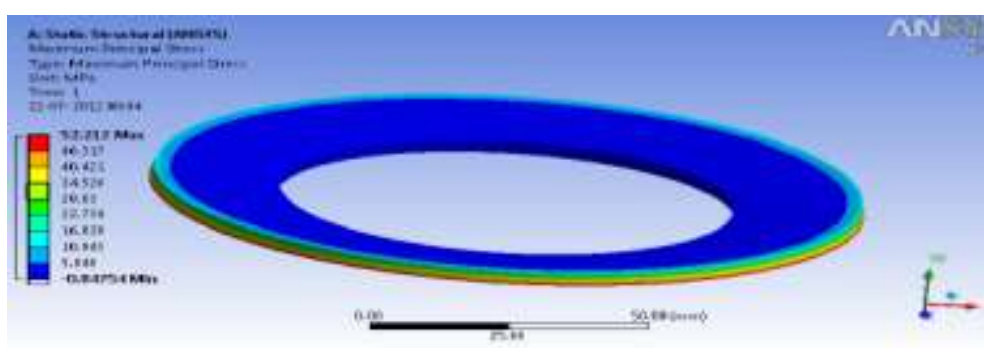

Figure 4: Maximum Principle Stress Contour at the outer Surface (MPa)

\section{Results}

The FE analysis revealed the principal stresses of outer and inner surface along with the deflections for various ratios of $\mathrm{D} / \mathrm{d}$ and $\mathrm{h} / \mathrm{t}$. The variation of deflection and principal stresses are shown in from figure 5 to figure 19.The principal stresses and deflections are also determined using analytical equations and its comparison are also shown in figure 5 to figure 19.

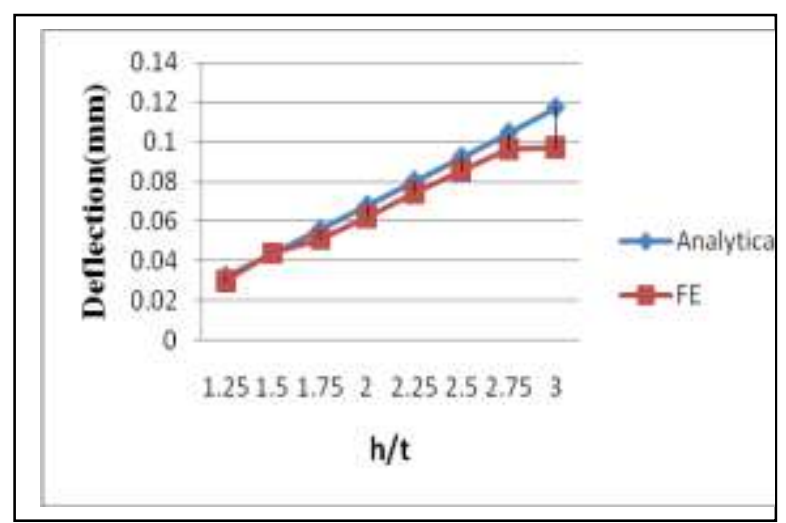

Figure 5: Deflection for $\mathrm{D} / \mathrm{d}=1.2$

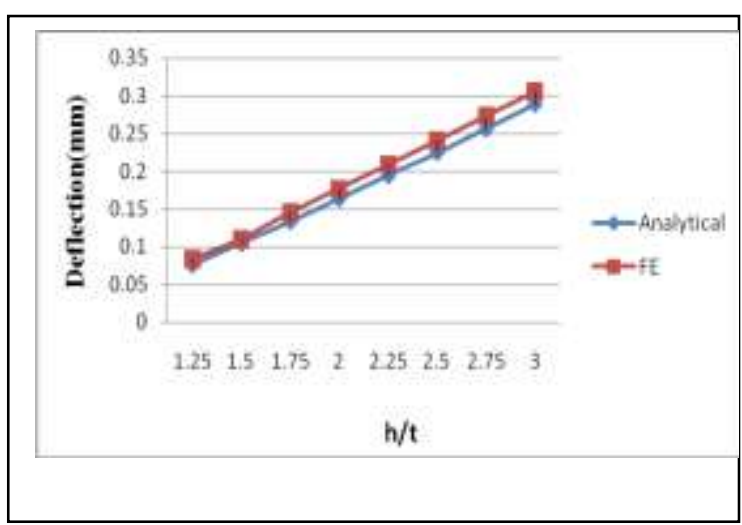

Figure 6: Deflection for $\mathrm{D} / \mathrm{d}=2$ 


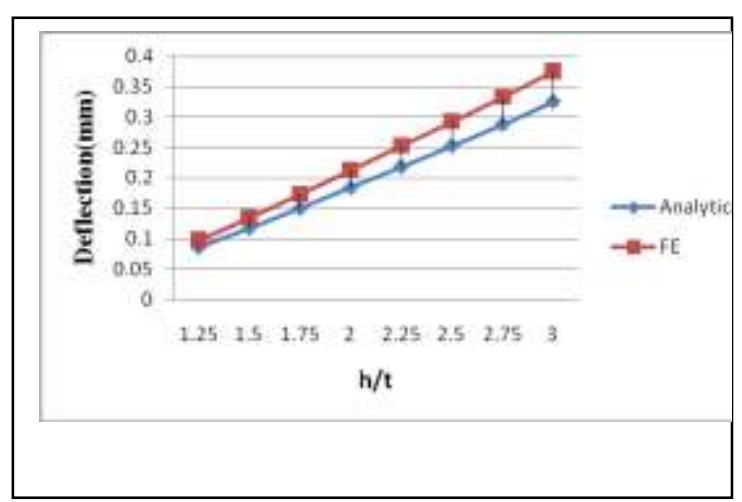

Figure 7: Deflection for $\mathrm{D} / \mathrm{d}=3$

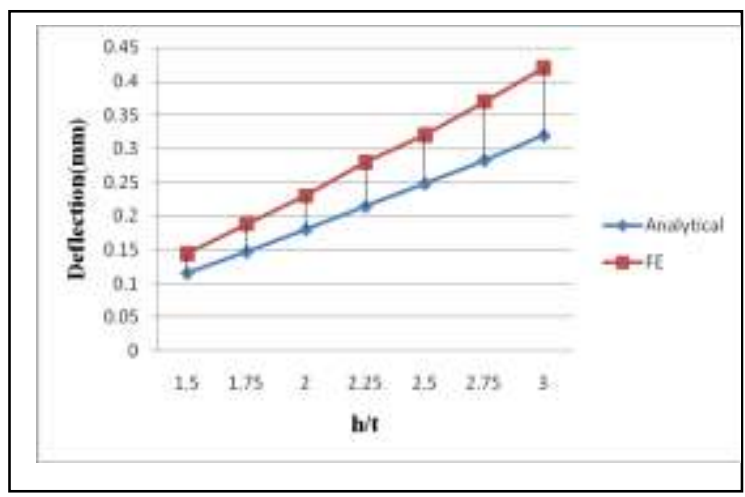

Figure 9: Deflection for $\mathrm{D} / \mathrm{d}=5$



Figure 11: Principal Stress on Inner Surface for $\mathrm{D} / \mathrm{d}=2$

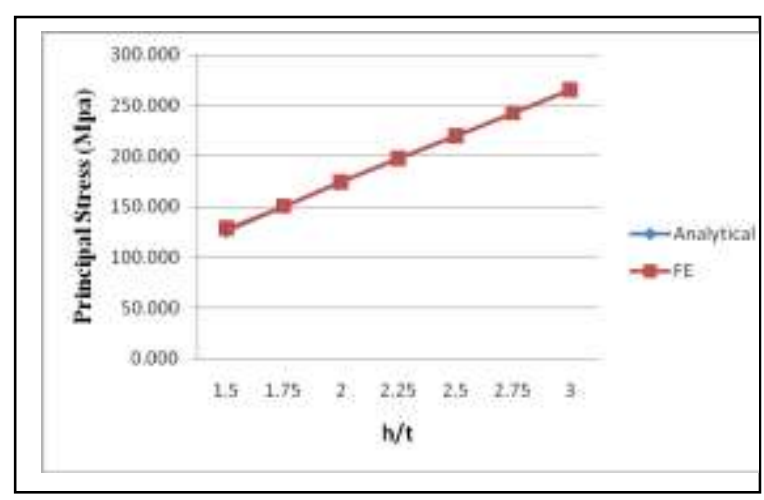

Figure 13: Principal Stress on Inner

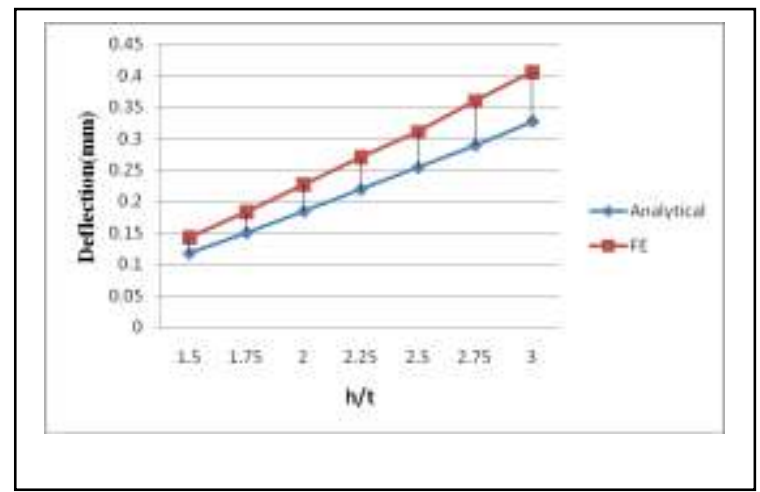

Figure 8: Deflection for $\mathrm{D} / \mathrm{d}=4$

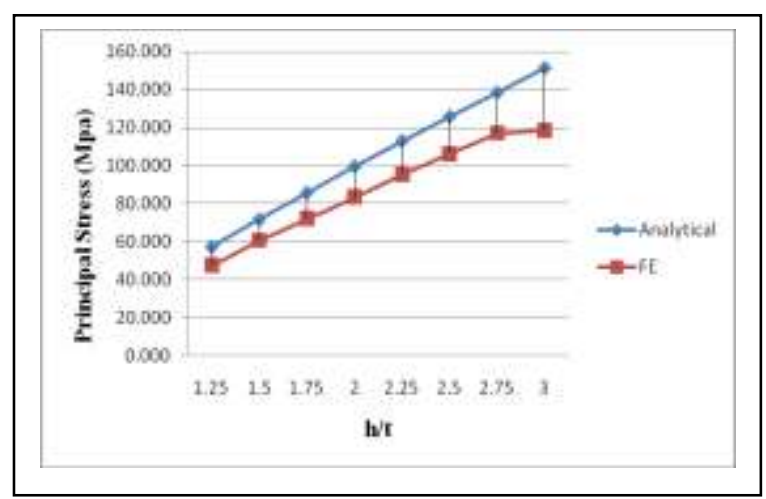

Figure 10: Principal Stress on Inner Surface for $\mathrm{D} / \mathrm{d}=1.2$

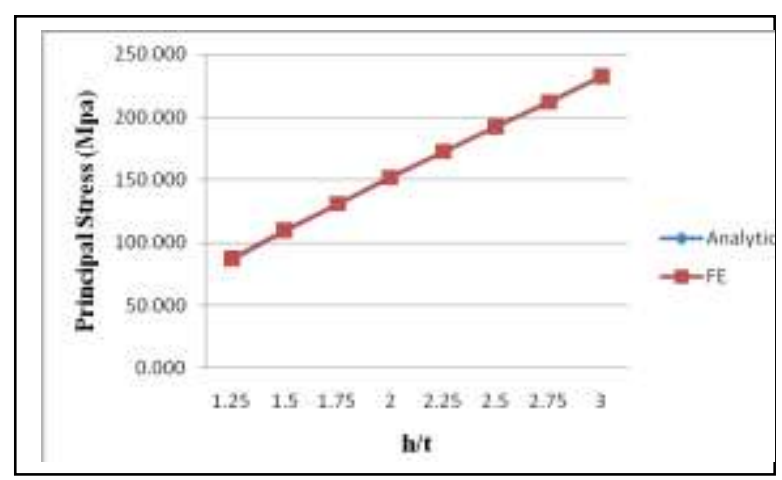

Figure 12: Principal Stress on Inner Surface for $\mathrm{D} / \mathrm{d}=3$

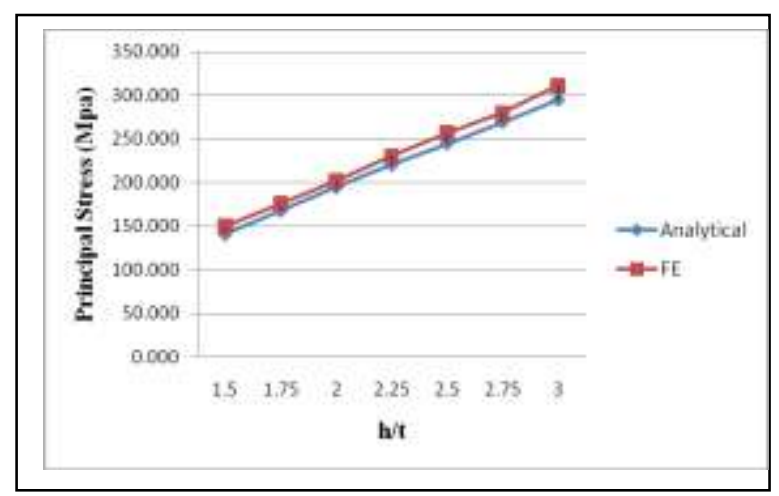

Figure 14: Principal Stress on Inner 


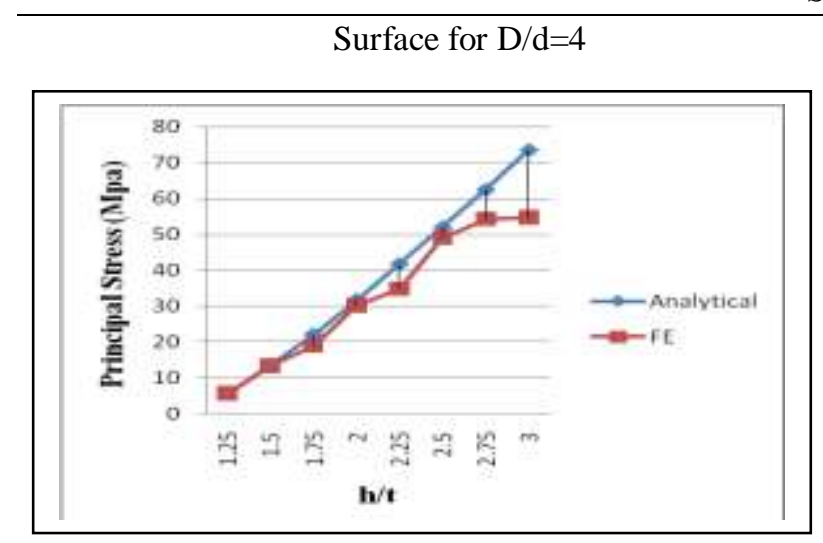

Figure 15: Principal Stress on Outer Surface for $\mathrm{D} / \mathrm{d}=1.2$

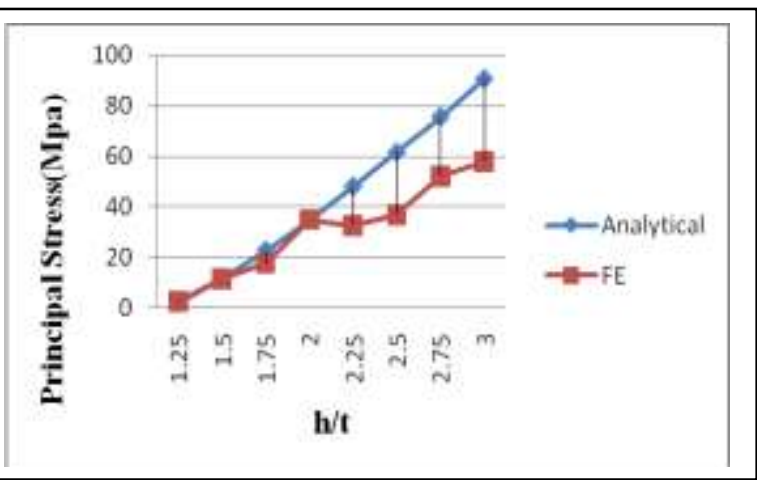

Figure 17: Principal Stress on Outer Surface for $\mathrm{D} / \mathrm{d}=3$
Surface for $\mathrm{D} / \mathrm{d}=5$

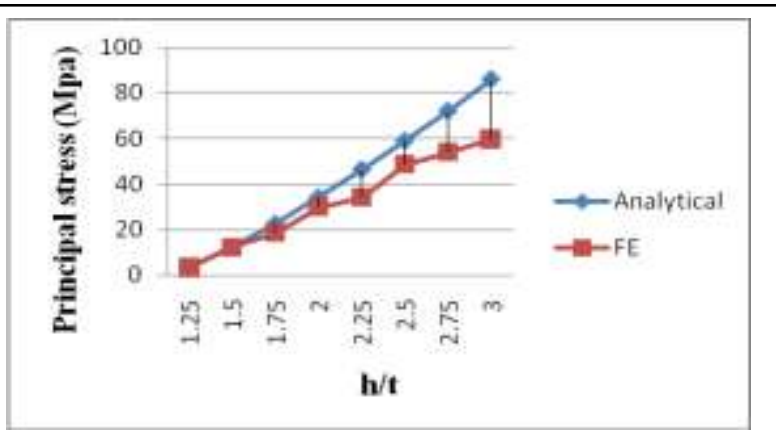

Figure 16: Principal Stress on Outer Surface for $\mathrm{D} / \mathrm{d}=2$

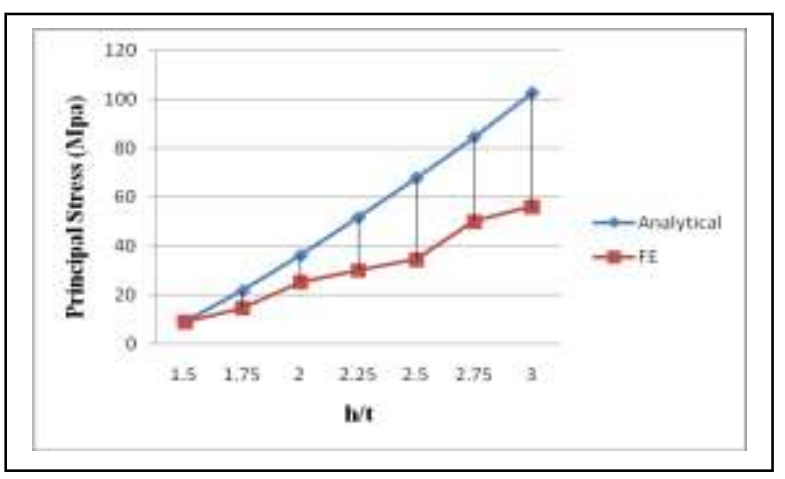

Figure 18: Principal Stress on Outer Surface for $\mathrm{D} / \mathrm{d}=4$

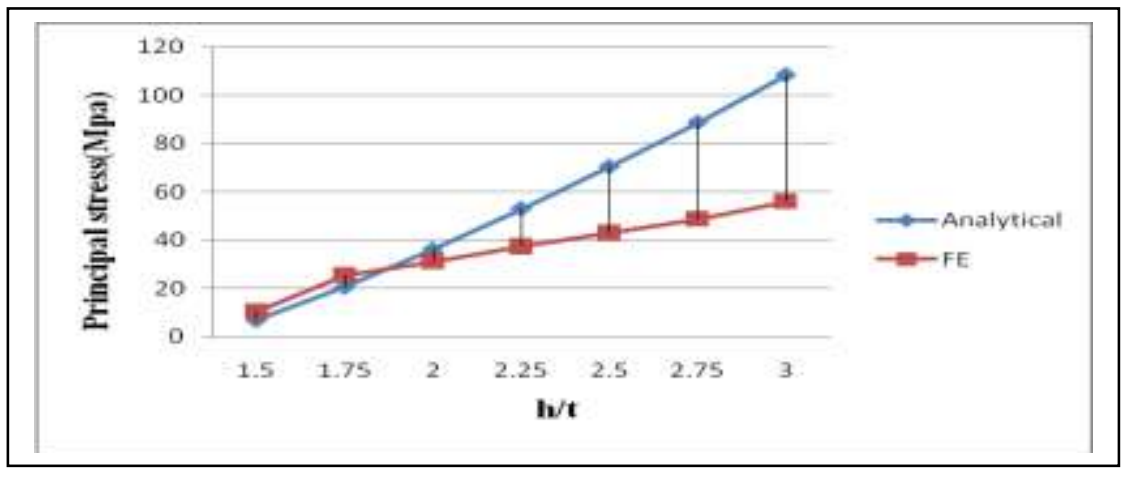

Figure 19: Principal Stress on Outer Surface for $D / d=5$

The load - deflection characteristics for $\mathrm{D} / \mathrm{d}=2 ; \mathrm{h} / \mathrm{t}=1.5$ and $\mathrm{D} / \mathrm{d}=4 ; \mathrm{h} / \mathrm{t}=1.5$ are shown in figure $20 \& 21$ respectively.

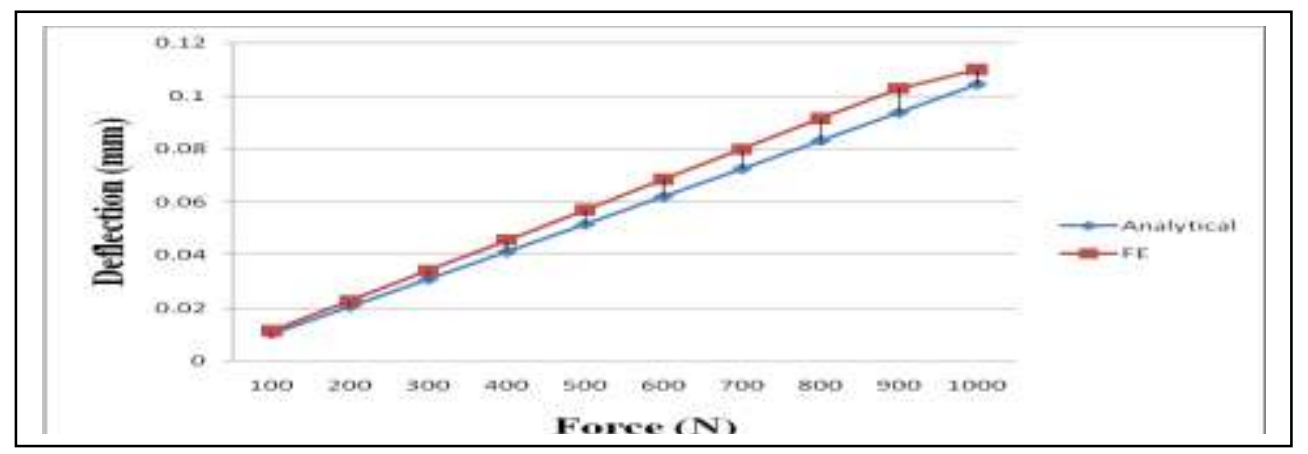

Figure 20: Load - Deflection Characteristic for $\mathrm{D} / \mathrm{d}=2 \& \mathrm{~h} / \mathrm{t}=1$. 


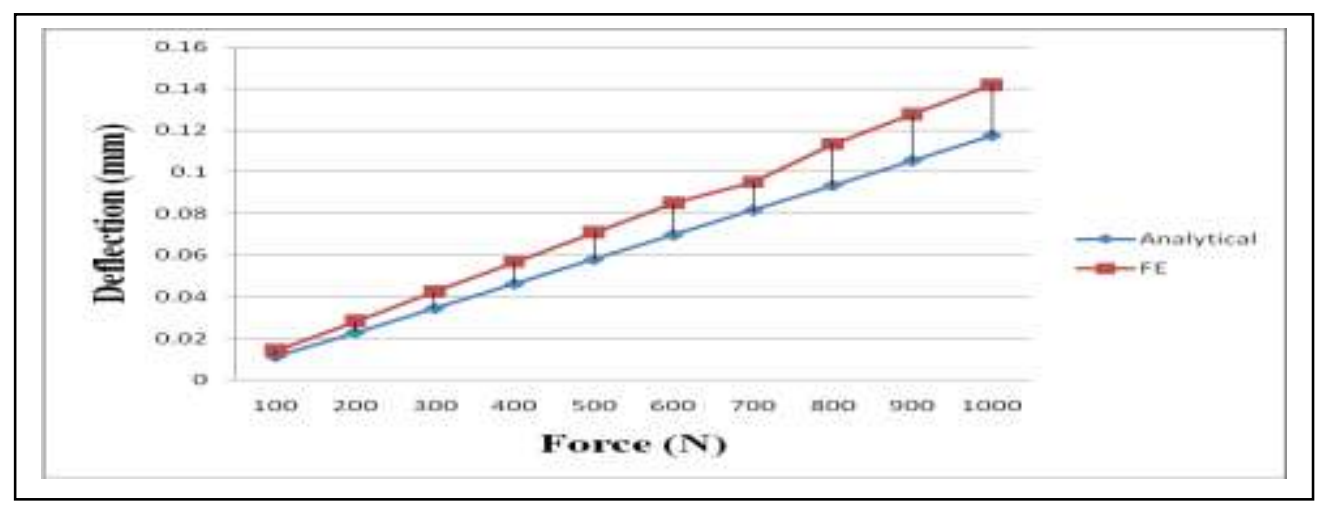

Figure 21: Load - Deflection Characteristic for $\mathrm{D} / \mathrm{d}=4 \& \mathrm{~h} / \mathrm{t}=1.5$

\section{Discussion And Conclusion}

1. It is observed from the figs.5, 6, 7, 8, and 9 that the nature of variation is similar between analytical and FE values for deflection. It is also observed that as the ratio of $\mathrm{D} / \mathrm{d}$ varies from 1.2 to 5 the deviation between analytical and FE values increases. It is also observed that for each ratio of $\mathrm{D} / \mathrm{d}$ as $\mathrm{h} / \mathrm{t}$ is increasing, the deviation between analytical and FE values is also increasing. This trend observed for deflection may be due to the following facts:

- As D/d ratio goes on increasing, the Conicality of the spring also increases. Due to this Bending stress predominates the axial compressive stress and this deviation may have occured.

- As $\mathrm{h} / \mathrm{t}$ increases the spring behavior approaches to that of a plate due to reduction in its thickness.

2. From the figs $10,11,12,13$ and 14 it can be observed that the principal stresses at the inner side of the spring is exactly same for the analytical calculations \& FE results with a few exceptions for all values of $\mathrm{D} / \mathrm{d} \& \mathrm{~h} / \mathrm{t}$.

3. From the figs. $15,16,17,18$ and 19 it is seen that the analytical values of principal stresses for the Outer surface are more than FE values for all ratios of D/d \& h/t. But as $h / t$ increases the deviation between analytical and FE values also increases. This trend is also observed for deflection.

4. From figs. 20 \& 21 i.e. load-deflection characteristic it is seen that the Belleville spring with lower ratio of $\mathrm{D} / \mathrm{d}$ has marginal deviation of deflection between analytical and FE values with the increase in magnitude of the force. However for higher ratios of $\mathrm{D} / \mathrm{d}$ the deviation of deflection between FE and analytical values is quiet noticeable. This is due to the non-linear behavior of the conical spring. Thus the analytical equations of deflection may become error prone for higher values of $\mathrm{D} / \mathrm{d}$ and $\mathrm{h} / \mathrm{t}$ for higher loads.

Thus, it can be concluded that the analytical equation for Belleville springs though estimates the maximum stresses and deflection for certain cases, but finite element analysis is recommended for accurate estimation of maximum stress and deflection in case of Belleville spring under given loading condition.

\section{References}

[1]. $\quad$ Almen. J. O., and Laszlo, A., "The Uniform Section Disk Spring," Trans. ASME, Vol. 58, 1936, pp. $305-314$.

[2]. Spotts, M. F., "Mechanical Design Analysis," Prentice Hall Inc., Englewood Cliffs, N. J., 1964, pp. 80-90.

[3]. Shigley J.E. "Mechanical engineerng design." McGraw-Hill International Edition (1986).

[4]. Wahl, A. M., "Mechanical Springs", McGraw Hill Book Co, New York, 1963, pp. 179-181.

[5]. Schremmer, G., "Endurance Strength and Optimum Dimensions of Belleville Springs," ASME-paper 68-WA/DE-9, 1968.

[6]. Belleville Springs_-Design Manual, E. C. Styberg Eng. Co., Racine, Wis.

[7]. Schnorr Disc Spring Handbook, Karl A. Neise Inc., Woodside New York. 